[6] Pogarska, V., Pavlyuk, R., Timofeyeva, N., Bilenko, L., Stukonozhenko, T. (2016). Elaboration of new method of deep processing of caro-tene-containing raw materials into nanoadditives with the use of cryogenic freezing and fine-dispersed grinding. EUREKA: Life Sciences, 6, 37-43. doi: http://doi.org/ 10.21303/2504-5695.2016.00251

[7] Tu, J., Zhang, M., Xu, B., Liu, H. (2015). Effects of different freezing methods on the quality and microstructure of lotus (Nelumbo nucifera) root. International Journal of Refrigeration, 52, 59-65. doi: http:// doi.org/10.1016/j.jijrefrig.2014.12.015

[8] Tuan Pham, Q. (2014). Freezing time formulas for foods with low moisture content, low freezing point and for cryogenic freezing. Journal of Food Engineering, 127, 85-92. doi: http://doi.org/10.1016/ j.jfoodeng.2013.12.007

[9] James, S. J., James, C. (2014). Chilling and Freezing. Food Safety Management, 481-510. doi: http://doi.org/10.1016/b978-0-12-381504-0.00020-2

[10] Evans, J. (2016). Emerging Refrigeration and Freezing Technologies for Food Preservation. Innovation and Future Trends in Food Manufacturing and Supply Chain Technologies. Woodhead Publishing, 175-201. doi: http://doi.org/10.1016/b978-1-78242-447-5.00007-1

[11] Min, K., Chen, K., Arora, R. (2014). Effect of short-term versus prolonged freezing on freezethaw injury and post-thaw recovery in spinach: Importance in laboratory freeze-thaw protocols. Environmental and Experimental Botany, 106, 124-131. doi: http://doi.org/10.1016/j.envexpbot.2014.01.009

\title{
INVESTIGATIONS OF THE FUNCTIONAL AND TECHNOLOGICAL PROPERTIES OF DOUGH SEMI- PRODUCTS ENRICHED WITH DIETARY SUPPLEMENTS
}

\author{
Tatyana Golovko
}

Department of commodity research in customs business Kharkiv State University of Food Technology and Trade 333 Klochkivska str., Kharkiv, Ukraine, 61051 golovko.tatyana.10@gmail.com

Micola Pogozhikh

Department of physical and mathematical and engineering-technical disciplines Kharkiv State University of Food Technology and Trade 333 Klochkivska str., Kharkiv, Ukraine, 61051 m.pogozhikh@hduht.edu.ua

\section{Andrey Pak}

Department of physical and mathematical and engineering-technical disciplines Kharkiv State University of Food Technology and Trade 333 Klochkivska str., Kharkiv, Ukraine, 61051 a.pak@hduht.edu.ua

\section{Nicolay Golovko}

Department of commodity research in customs business Kharkiv State University of Food Technology and Trade 333 Klochkivska str., Kharkiv, Ukraine, 61051 golovko.m.p@ukr.net

\section{Alina Pak}

Department of merchandising and examining the quality of goods Kharkiv Institute of Trade and Economics of Kyiv National University of Trade and Economics 8 Otakara Yarosha str., Kharkiv, Ukraine, 61045 pak.alina1984@gmail.com 


\author{
Myushfik Bakirov \\ Kharkiv College of Trade and Economics of Kiev National University of Trade and Economics. \\ 202 Klochkivska str., Kharkiv, Ukraine, 61045 \\ bakirov_mp@ukr.net
}

\begin{abstract}
The work is devoted to improving technologies of enriching food raw materials and products. The object of the research is dough semi-products of leavened, puff and unleavened dough, enriched with a dietary supplement, based on the chelate complex. The conducted studies are directed on investigating the evenness of distribution of microelements in the volume of dough semi-products and establishing the influence of a supplement on functional-technological properties of these semi-products. At that there were used methods of nuclear magnetic resonance, electronic paramagnetic resonance, low-temperature calorimetric method and rheological research methods. The method of nuclear magnetic resonance established that a dietary supplement, based on the chelate complex influences the mobility and interaction of water molecules with an environment in dough semi-products. The method of electronic paramagnetic resonance proved the evenness of distribution of a microelement of a dietary supplement by the volume of studied dough semi-product. Rheological and low-temperature calorimetric methods established that an introduced supplement favors a change of the qualitative and quantitative composition of system water of studied semi-products and changes their elastic properties. The obtained results proved the efficiency of using a powder-like supplement with stabilized chelates of metals in technologies of enriching food products.

Keywords: dietary supplement, based on chelate complex, dough semi-products, functional-technological properties of dough.

\title{
1. Introduction
}

The difficult economic situation, formed in Ukraine and throughout the world, resulted in the fact that most population has no possibility to feed with full-value food products [1]. The simplest way of improving the quality of the people's food ration is to enrich food products with vitamins and mineral substances [2].

At that the urgent problem of technologies of enriching food products is a choice of a carrier of a chemical element and even distribution of this carrier in a product [3]. Microelements are introduced in food products and raw materials by dry mixing with elements [4], dilution in a liquid phase [5], application of special covers [6], and so on. But provision of the homogeneity of distribution of introduced microelements in the volume of a food product remains an unsolved question. One of methods that allow to solve it is the use of dietary supplements based on chelate complexes, in food technologies [7]. This direction is new in food technologies and needs experimental studies. That is why the aim of the work is to study the evenness of distribution of microelements in the volume of dough semi-products and influence of a supplement on functional-technological properties of these semi-products. It allows to manage functional-technological properties of dough semi-products with introduced dietary supplements, based on chelate complexes, in technologies on enriching food products reasonably.

\section{Material and methods of research}

\section{1. Studied materials and equipment, used in the experiment}

Determinations of distribution of a powder-like dietary supplement, based on the chelate complex, in the volume of the food system and its influence on functional-technological properties of the studied food systems were realized in four stages corresponding to the used method. The following methods were used at that: nuclear magnetic resonance (NMR), electronic paramagnetic resonance (EPR), low-temperature calorimetric method and rheological research methods. The metal ion, which distribution was studied, was $\mathrm{Mn}^{2+}$.

The food system that were a subject of the rheological studies and ones by the low-temperature calorimetric, NMR, EPR methods is a food raw material with introducing a supplement, based on the chelate complex $\mathrm{Mn}^{+2}$ : 
- model system No. 1 (leavened dough - with moisture content 0,43 rel.un.;

- model system No. 2 (puff dough) - with moisture content 0,29 rel.un.;

- model system No. 3 (unleavened dough) - with moisture content 0,35 rel.un.

Model systems 1, 2, 3 without introducing a supplement, based on the chelate complex $\mathrm{Mn}^{+2}$ were used as a control.

In the NMR studies there was used an impulse radiospectrometer for laboratory studies that functions with fixed frequency $16,5 \mathrm{MHz}$ [8].

For studying system water of the food raw materials and products, there was used a laboratory low-temperature calorimeter [9] (Fig. 1), developed in Kharkiv state university of food and trade using analogous-digital transformers, produced by DCON Utility (USA).

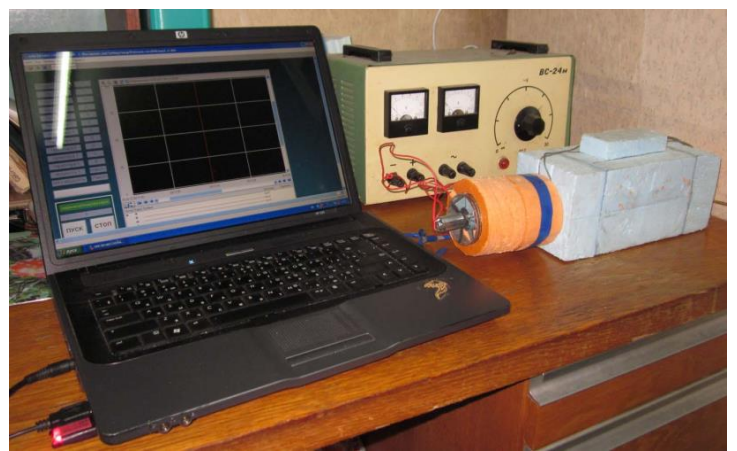

Fig. 1. Laboratory low-temperature calorimeter with analogous-digital transformers, produced by DCON Utility (USA)

The rheological studies were realized on Tolstoy flat-parallel elastoplastometer [10] (Fig. 2).

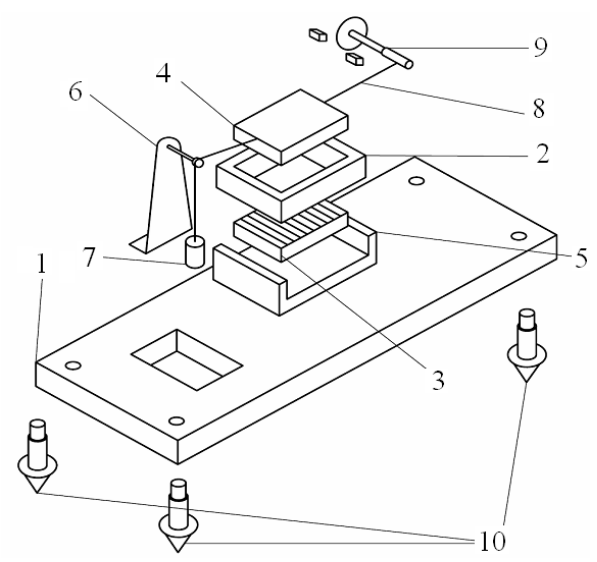

Fig. 2. Modernized Tolstoy elastoplastometer: 1 - stand; 2 - right-angled form as a parallelogram; 3, 4 - rifled lexiglass plates; 5 - body; 6 - console; 7 - load; 8 - flexible connection;

9 - sensor of linear displacements; 10 - supports

For registering EPR spectrums, there was applied a radiospectrometer that functions on the fixed wave length $\lambda=3,2 \mathrm{~cm}$. Spectrums were registered as a first derivative of absorbing energy of the ultra high frequency $\mathrm{E}$ by the studied paramagnet at scanning the constant magnetic field $\mathrm{H}[11]$.

\section{2. Experiments}

NMR-studies were conducted in two stages: the study of the mobility of molecules by measuring a time of spin-spin relaxation $\left(\mathrm{T}_{2}\right)$ spin-lattice relaxation $\left(\mathrm{T}_{1}\right)$.

Time $\left(\mathrm{T}_{2}\right)$ determination was conducted in the following way. A sample with the studied material was placed in a radiofrequency bobbin, placed in the constant magnetic field. At radiating 
a sample by the changeable magnetic field with frequency $16,5 \mathrm{MHz}$ [12] a response appeared in a bobbin, conditioned by the structure of the studied system.

Two impulses with an interval $\tau_{\mathrm{i}}$ were given on the studied sample. The first impulse returns magnetic moments on angle $90^{\circ}$, another one - on angle $180^{\circ}$. After stopping the effect of a radiofrequency impulse in time $2 \tau_{i}$, an echo signal, conditioned by returning magnetic moments in the initial state under the effect of the constant magnetic field, appears.

The amplitude of a signal at the output of NMR spectromenter was determined by the expression:

$$
\mathrm{A}(2 \tau)=\mathrm{A}_{0} \cdot \mathrm{e}^{-\frac{2 \tau}{\mathrm{T}_{2}}}
$$

where $A(2 \tau)$ - signal on the spectrometer output, rel.un.; $A_{0}$ - initial amplitude of a signal, rel.un.

For determining the value of $T_{2}$, studied at the interval between probing impulses $\tau$, and $\mathrm{A}_{0}$ of a sample, a series of experiments, at which the echo signal amplitude value is fixed after the influence of two probing impulses with different values $\tau_{\mathrm{i}}$ was realized.

Measuring the echo signal amplitude at different values of $\tau_{i}$ there was determined the time of spin-spin relaxation and assessed the mobility of water, kept by a sample. The example of oscillograms of NMR signal, that $\mathrm{T}_{2}$ value is calculated by, is presented on Fig. 3. The first oscillogram (1) presents the echo signal at the minimal value $\tau_{i}$, The last (3) oscillogram presents the echo signal at the maximal value $\tau_{\mathrm{i}}$.

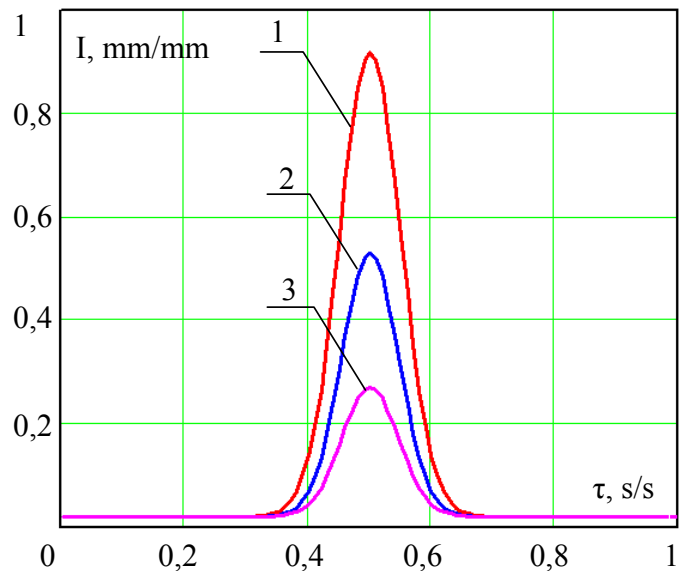

Fig. 3. Oscillograms of signals of NMR spectrometer at different intervals between probing impulses $\left(\tau_{\mathrm{i}}\right): 1-$ minimal $\tau_{\mathrm{i}} ; 2-$ middle $\tau_{\mathrm{i}} ; 3-$ maximal $\tau_{\mathrm{i}}$

Based on data, obtained as a result of measuring, there was built a curve of the dependence of the echo signal amplitude on the value $\tau_{\mathrm{i}}$ (time interval between probing impulses). The dependence of the echo signal amplitude on the value $\tau_{i}$ is presented on Fig. 4. It has the exponential character. $T_{2}$ value was determined by expression (1) based on the curve on Fig. 4.

For determining the time of spin-spin relaxation $\left(\mathrm{T}_{1}\right)$ there was used the method, based on Khan two-impulse method [12]. The echo signal amplitude after the effect of the second couple of impulses was determined by the formula:

$$
\mathrm{A}\left(\mathrm{t}_{\mathrm{i}}+3 \tau_{\mathrm{i}}\right)=\mathrm{A}_{0}\left(1-\mathrm{e}^{-\frac{\left(\mathrm{t}_{\mathrm{i}}+3 \tau_{\mathrm{i}}\right)}{\mathrm{T}_{1}}}\right)
$$

where $\tau_{\mathrm{i}}$ - interval between probing impulses by Khan method, $\mathrm{s} ; \mathrm{t}_{\mathrm{i}}-$ interval between two successions of probing impulses of Khan method, s.

The experiment fixed the picture of spin echo (as two impulses) in a time moment, equal to $\tau_{\mathrm{i}}$ and $\tau=\mathrm{t}_{\mathrm{i}}+3 \tau_{\mathrm{i}}$. The example of the general outlook of the oscillogram, rationed for the maximal value of amplitude and time, is presented on Fig. 5. The echo signal from the first 
probing succession has an equal value, and the impulse from the second succession increases with changing the value $t_{i}$.

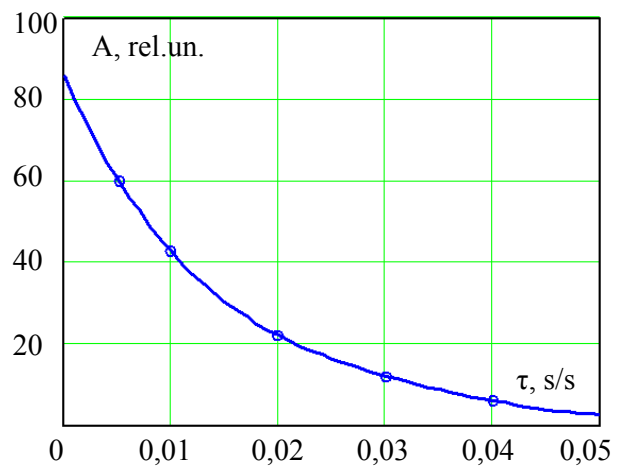

Fig. 4. Dependence of the echo signal amplitude (A) on the interval between probing impulses $\tau_{\mathrm{i}}$

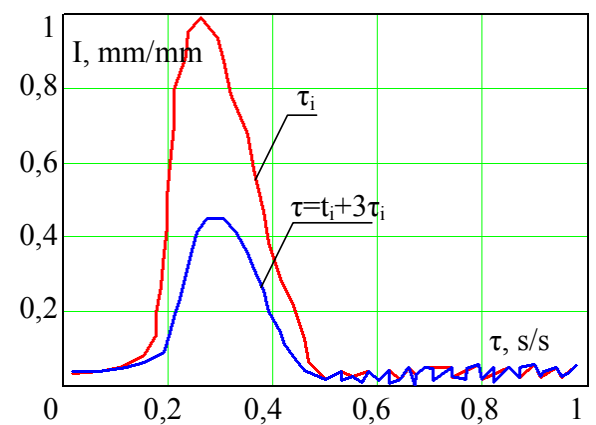

Fig. 5. Outlook of oscillograms at determining the time of spin-lattice relaxation

The assessment of the homogeneity of volumetric distribution of a supplement, based on chelate compex $\mathrm{Mn}^{+2}$, introduced in the food system, was made by the method of EPR-marks. The assessment of distribution of a supplement by the volume of the food system is possible due to ion $\mathrm{Mn}^{+2}$, included in a supplement. Ion of the transition metal $\mathrm{Mn}^{+2}$ is used in this study as a spin mark for the method of EPR-spin marks [13].

EPR-signal of the spin-marked food system (1 on Fig. 6) in formed of two: a wide single line without an ultra-thin stricture ( 2 on Fig. 6) and divided spectrum of six peaks of the equal intensity ( 3 on Fig. 6). The area under the wide single line without an ultra-thin structure is proportional to the number of resounding spins of electrons of $\mathrm{Mn}^{+2}$ salt that contains this ion in the crystal form, so, to the mass of residual salt. The area under the divided spectrum of six peaks of the equal intensity is proportional to the number of spins of electrons of $\mathrm{Mn}^{+2}$ ions that are in the solution, so to the mass of moisture that manifest itself as a solvent.

Bind of water or its release in any case result in displacing the balance "ionic salt in the crystal form $\leftrightarrow$ ionic salt in the solved form", so to the left or to the right with creating non-dissociated molecules or ions. In its turn, it results in the increase of the area under the singe line or under the divided spectrum of six peaks with the equal intensity.

Thus, the analysis of spectrums, obtained from the studied food systems, gives a possibility to study the homogeneity of distribution of ion $\mathrm{Mn}^{+2}$, so the homogeneity of a supplement distribution along the volume of the food system, which it is introduced in.

The study of system water of food raw materials was conducted by the low-temperature calorimetric method. It is known that temperatures of water crystallization (phase transfer of I kind) or its transfer from the liquid form to the amorphous (phase transfer of II kind) are conditioned by the form of its connection with dry substances [14]. Based on it, there was fixed the temperature of phase transfer and the amount of heat, emitted at cooling a sample of the studied food system. At that there is a possibility of analyzing system water for the qualitative 
and quantitative assessment of forms and types of its connection with dry substances of this food system.

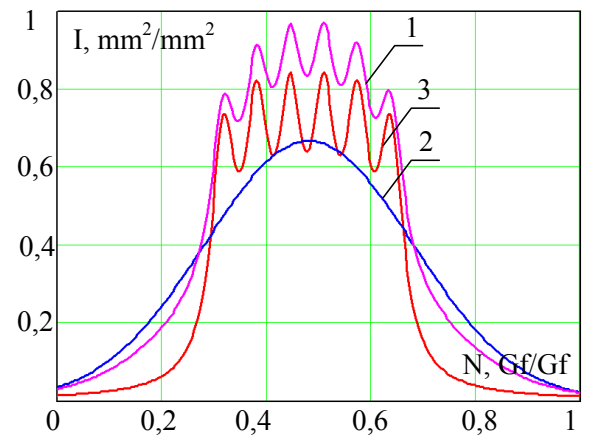

Fig. 6. Integrated EPR-spectrums for:

1 - food system; 2 - powder of ionic salt with $\mathrm{Mn}^{+2} ; 3$ - solution that retains ion $\mathrm{Mn}^{+2}$

Fig. 7 presents the thermogram, obtained at freezing a wet sample at the balanced temperature of the calorimeter, equal to $-12{ }^{\circ} \mathrm{C}$. The difference of temperatures $(\Theta)$ between the input and output of the calorimeter is presented on the ordinate axis, on the abscissa axis - time $(\tau)$ in relative units (rationed for the total duration of the process).

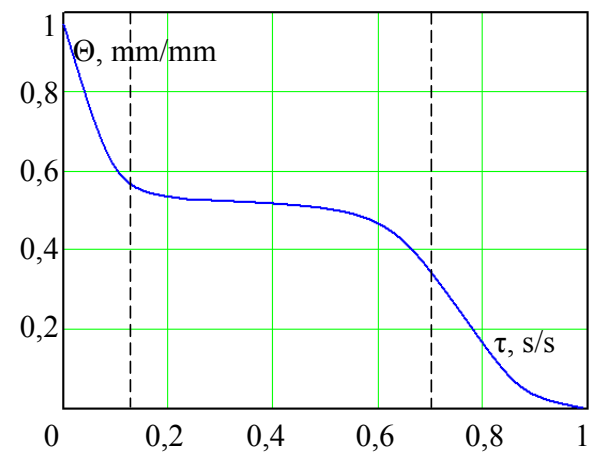

Fig. 7. Change of temperature difference $(\Theta)$ between the input and output of the calorimeter by time $(\tau)$

Based on the type of curve, it can be divided in three typical parts, separated by dotted lines from each other on fig. 6 . The area under the first part (I) is proportional to the amount of heat, emitted at cooling the object to the temperature of free water crystallization $\left(0^{\circ} \mathrm{C}\right)$. The area under the second part of the curve (II) corresponds to the amount of heat, emitted at free water crystallization (temperature of phase transfer of I kind is $0{ }^{\circ} \mathrm{C}$ ). The area under the third one (III) - to the amount of heat, emitted at cooling of a sample to the final temperature of the calorimeter.

At the rheological studies, there was determined the shift deformation, related to the width of a sample [10]. The first value of absolute deformation was obtained instantly, as soon as a load begins to affect the upper plate. After that values of absolute deformation were taken each $1 \mathrm{~min}$ during $10 \mathrm{~min}$. The further observations were made each $5 \mathrm{~min}$. After unloading, the instant deformation was fixed, then indications of the devices were taken with the same frequency than at uploading. The studies were stopped, if the change of absolute deformation was not fixed during $30 \mathrm{~min}$. For determining structural-mechanical indices, the change of relative deformation was built with the time of tension effect $\gamma=\mathrm{f}(\mathrm{t})$ (Fig. 8).

Then there was calculated the relative deformation, ratio coefficient of reverse deformation to the total one, shift tension, pliability of the system, module of instant elasticity, plastic viscosity, viscosity of the firm aftereffect. 


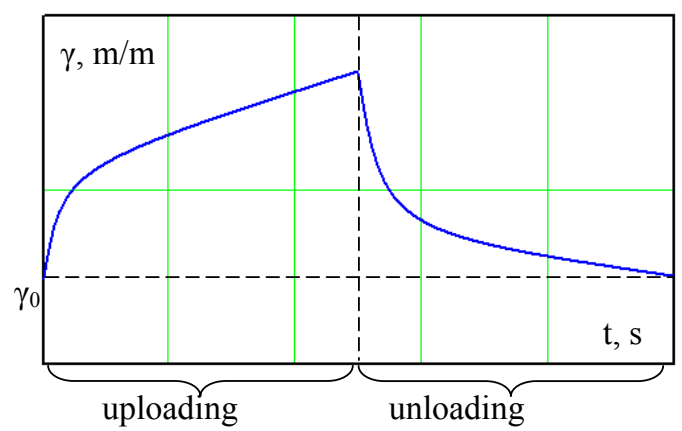

Fig. 8. Change of relative deformation $(\gamma)$ with time $(t)$

\section{Results}

The NPR-studies established the following. The interaction between water molecules in the control sample of unleavened dough (without adding a dietary supplement, based on the chelate complex) is less than in the dough sample with a supplement $(0,004 \mathrm{~s})$, and is $0,013 \mathrm{~s}$. As to spin-lattice relaxation, the interaction of dough with other molecules (ones of the external environment) decreased in unleavened dough at adding a supplement and the time of spin-lattice relaxation increased from 0,03 to $0,05 \mathrm{~s}$. For puff dough, the interaction between water molecules is manifested in more degree for the dough sample without adding a supplement: the time of spin-spin relaxation is $0,01 \mathrm{~s}$, and at adding a supplement- $0,03 \mathrm{~s}$. The interaction between dough and other molecules is more in the sample of puff dough with a supplement $(0,008 \mathrm{~s})$ comparing with the sample of dough without a supplement $(0,025 \mathrm{~s})$. The interaction between water molecules in leavened dough without a supplement is manifested less $(0,016 \mathrm{~s})$ comparing with the sample of dough with the same supplement $(0,015 \mathrm{~s})$. At adding a supplement, the dough interaction with external molecules decreased and the time of spin-spin relaxation grew from 0,06 to $0,065 \mathrm{~s}$. It is necessary to note that the less time of spin-spin relaxation, the stronger interaction between water and external environment is.

The studies by the method of EPR-spin marks demonstrated that any break of the ultra-thin structure of EPR spectrum wasn't observed in samples. It means that at such state of samples, stabilized chelate is mainly in the saturated state. Such state corresponds to the decrease of the value of dielectric permeability of the medium, in which result chelate loses solubility. The EPR studies established that the amount of the introduced supplement for the volume of the food system differs no more than by $4 \ldots .5 \%$. This result proves the homogeneity of distribution of the microelement $(\mathrm{Mn})$ of a dietary supplement for the volume of dough semi-products.

The low-temperature calorimetric method established that the amount of unfrozen water for leavened dough increased in 1,7 times; for puff one - in 1,2 times; for unleavened - in 1,4 times. It indicates the increase of the amount of bound water at adding a supplement. The established result is an initial condition at determining storage conditions for dough semi-products.

The rheological studies established that the reverse deformation in unleavened dough is more in the control sample and is $0,04 \cdot 10^{-3}$, comparing with the sample with a supplement, where it is $0,01 \cdot 10^{-3}$. For leavened dough in the control sample the reverse deformation is $0,06 \cdot 10^{-3}$, and with a supplement $-0,04 \cdot 10^{-3}$. The irreversible deformation in unleavened dough in the control sample is less $\left(0,02 \cdot 10^{-3}\right)$, than in the sample with a supplement $\left(0,05 \cdot 10^{-3}\right)$. The total deformation in unleavened dough in the control sample is $0,04 \cdot 10^{-3}$, in the sample with a supplement $-0,05 \cdot 10^{-3}$; in leavened dough in both cases $-0,08 \cdot 10^{-3}$. The sample with the most relative elasticity - leavened dough with a supplement with the percent of relative elasticity $-25,60 \%$. The control sample of leavened dough has the high relative elasticity $-21,74 \%$. As to unleavened dough - the relative elasticity is much more in the control sample - 19,27\%, comparing with the sample with a supplement $13,19 \%$. The relative elasticity in both cases in unleavened and leavened dough is more in the samples with an introduced supplement. Thus, in unleavened dough it is $-86,54 \%$, in leavened $54,22 \%$, in the control samples, respectively, $-20,11 \%$ and $20,96 \%$. The rheological studies of dough semi-products with a supplement testify to the change of elastic properties of the studied food systems with introducing a dietary supplement, based on the chelate complex. 


\section{Conclusions}

The low-temperature calorimetric and rheological methods, NPR, EPR studies of functional-technological properties of dough semi-products, enriched with dietary supplements, based on the chelated complex, gave the following results.

1. It was established, that a dietary supplement, based on the chelate complex influences the mobility and interaction of water molecules of dough semi-products before the interaction with air molecules, particles of a powder-like dietary supplement, based on the chelate complex, lipids, proteins and so on.

2. It was established, that distribution of a dietary supplement, based on the chelate complex with $\mathrm{Mn}$ for the volume of dough semi-products is homogenous. It was noted, that stabilized chelate is mainly in the saturated state, because water of dough semi-products is in the "bound" state.

3. It was established, that there takes place the increase of the amount of unfrozen water for dough samples at introducing a dietary supplement, based on the chelate complex, comparing with the control. It testifies to the increase of the amount of bound water at introducing a supplement.

4. It was established, that the change of elastic properties takes place in dough semi-products with a dietary supplement.

The research results may be used in technologies of enriching food products and introduced at enterprises of producing bakery, confectionary, macaroni products. The result of such introduction will be the new technology of enriching food products and widening their assortment.

\section{References}

[1] Mostenska, T. H. (2014). Pryntsypy zbalansuvannia prodovolchoi bezpeky. Kyiv: KondorVydavnytstvo, 360.

[2] Smoliar, V. I., Petrashenko, H. I., Holokhova, O. V. (2014). Fortyfikatsiya kharchovykh produktiv. Problemy kharchuvannia, 1, 29-32.

[3] Hashemi Gahruie, H., Eskandari, M. H., Mesbahi, G., Hanifpour, M. A. (2015). Scientific and technical aspects of yogurt fortification: A review. Food Science and Human Wellness, 4 (1), 1-8. doi: https:// doi.org/10.1016/j.fshw.2015.03.002

[4] Akhtar, S., Anjum, F. M., Anjum, M. A. (2011). Micronutrient fortification of wheat flour: Recent development and strategies. Food Research International, 44 (3), 652-659. doi: https://doi.org/10.1016/ j.foodres.2010.12.033

[5] Özer, B. H., Kirmaci, H. A. (2010). Functional milks and dairy beverages. International Journal of Dairy Technology, 63 (1), 1-15. doi: https://doi.org/10.1111/j.1471-0307.2009.00547.x

[6] Betoret, E., Betoret, N., Vidal, D., Fito, P. (2011). Functional foods development: Trends and technologies. Trends in Food Science \& Technology, 22 (9), 498-508. doi: https://doi.org/10.1016/j.tifs.2011.05.004

[7] Pogozhikh, N., Golovko, T., Pak, A., Dyakov, A. (2017). Study of regularities of distributing powdered dietetic additives in coarse dispersed foodstuffs. Food science and technology, 11 (4), 72-80. doi: https://doi.org/10.15673/fst.v11i4.733

[8] Laghi, L., Picone, G., Capozzi, F. (2014). Nuclear magnetic resonance for foodomics beyond food analysis. TrAC Trends in Analytical Chemistry, 59, 93-102. doi: https://doi.org/10.1016/j.trac.2014.04.009

[9] Pak, A. O., Yevtushenko, A. V. (2010). Doslidzhennia stanu volohy pastopodibnykh napivfabrykativ u protsesi zamorozhuvannia, rozmorozhuvannia, zberihannia. Eastern-European Journal of Enterprise Technologies, 3 (10(45)), 54-56. Available at: http://journals.uran.ua/eejet/article/view/2909/2712

[10] Jekle, M., Becker, T. (2014). Wheat Dough Microstructure: The Relation Between Visual Structure and Mechanical Behavior. Critical Reviews in Food Science and Nutrition, 55 (3), 369-382. doi: https:// doi.org/10.1080/10408398.2012.656476

[11] Lund, A., Shiotani, M. (2008). Principles and Applications of Electron Spin Resonance. Springer Verlag, 367.

[12] Kirtil, E., Oztop, M. H. (2015). 1H Nuclear Magnetic Resonance Relaxometry and Magnetic Resonance Imaging and Applications in Food Science and Processing. Food Engineering Reviews, 8 (1), 1-22. doi: https://doi.org/10.1007/s12393-015-9118-y

[13] Bender, C. J., Berliner, L. J. (2006). Computational and Instrumental Methods in EPR, in Biological Magnetic Resonance. Springer Verlag, 387.

[14] Pogozhykh, M. I., Pak, A. O., Chekanov, M. A., Ishtvan, Ye. O., Pavliuk, I. M. (2014). Researches of system water of food raw materials by thermodynamic and molecular-kinetic methods. Eastern-European Journal of Enterprise Technologies, 5 (11 (71)), 42-46. doi: https://doi.org/10.15587/1729-4061.2014.27790 